\title{
Estimation of Weight at 32 Weeks of Age using Weight at Week 4 (w4), Weaning Weight (w8) and Weight at 20 Weeks of Age (w20) in Crossbred (Landly) Pigs
}

\author{
A. Kumari*, T. Dutt and A. Kumar \\ Division of Livestock Production Management, ICAR-IVRI, Bareilly, India \\ *Corresponding author
}

\begin{tabular}{|l|}
\hline Ke y w or d s \\
Pig, Weight, \\
Estimation, Growth \\
\hline Article Info \\
\hline $\begin{array}{l}\text { Accepted: } \\
\text { 07 November } 2020 \\
\text { Available Online: } \\
\text { 10 December } 2020\end{array}$ \\
\hline \hline
\end{tabular}

A B S T R A C T

Data on a total of 215 crossbred Landly pigs was obtained for the years 2015-2018 to estimate body weight at 32 weeks of age from body weights at different ages viz. 4 weeks (w4), 9 weeks (w8) and 20 weeks (w20) of age. The data comprised of weights at weekly intervals till 8th week and after 8 weeks of age, weights recorded at the interval of 4 weeks till 32 weeks of age. Data was categorized into male (69) and female pigs (146) and was fed to a program in the Statistical Analysis Software, MATLAB 2019b.Analysis was conducted individually on the group of male pigs, female pigs as well as combined dataset using weight at 4 weeks, weaning weight and weight at 20 weeks of age to determine which can be best used for prediction. Gradient or difference in weight was calculated. This was further used to calculate the average growth rate and was fed to the formula devised to find the estimated weight at week 32 . The estimated weights were used to calculate the average error and standard error to analyze the reliability of the estimation. Prediction from weight at week 20 produced the lowest standard error. In all the age groups females have shown better predictive ability than males. Results of estimation are similar both for pigs of week 4 age group and pigs of week 8 age group.

\section{Introduction}

Weight is an important index for assessment of growth performance in animals as well as in determining the health status of an animal. Regular weighing of animals not only helps to decide the proper amount of feed for the animals and avoid underfeeding or overfeeding but also to monitor the growth rate. Correct dose of therapeutics to treat animal diseases are decided on the basis of body weight to avoid the risk of under dose or overdose. It also helps to determine the possible value of the animal in relation to the market price.

Intensive animal husbandry is the need of time and this has led to automation in animal management systems to monitor the health and production status of the animals to fulfil market demands (Morris et al., 2012). All the important farm management decisions rest on the accurate and efficient monitoring of weight gain and growth performance of the 
animals. Slow or poorly growing animals can be easily weeded out or culled. Optimum nutrition, herd health and prediction and control of shipping weights are directly related to the knowledge of weight gain (Schofield et al., 1999). There are two methods available for weight estimation in farm and domestic animals. The direct method involves the manual weighing of the animals on a weighing platform. This method requires labor, can cause changes in the feeding behaviour of pigs due to stress and might lead to weight loss, chances of injury both to the animal and the handler. Results can still be in accurate due to constant physical contact of the machine with the animal and the dirty environment (Brandl and Jørgensen, 1996). Animals usually tend to defecate and contaminate the platform. Since the manual weighing is cumbersome process, it is therefore done only at the beginning and end of a production period for a representative subset of animals (Schofield, 1990). When manual weighing is not feasible due to unavailability of the weighing platform, alternative measures of weight detection are employed. Indirect method involves visual estimation of weight using linear body measurements, and image-analysis based weight prediction (Zaragoza et al., 2009). These are non- invasive methods and involve the use of statistical techniques for weight estimation.

The objective of our study was to establish the relationship between weights at 4,8 and 20 weeks of age and adult weight (week 32) in Landly pigs. This shall enable to ensure that weight at which age can be a better predictor of adult or marketing weight. Once the right age is established it shall give a positive impetus to the management strategies in the direction of uniform growth and efficient marketing. Both resources and expertise can be directed to the animals which show higher production potential and are expected to give a better growth rate and higher returns in future. The ability to estimate final weight at an early age will save the unnecessary expenses and facilitate weeding of weak and slow growing animals. Economy of the farm shall be greatly improved.

\section{Materials and Methods}

To estimate body weight at 32 weeks of age from body weights at different ages viz. 4 weeks, 8 weeks and 20 weeks of age the data was collected from the history-cum-pedigree sheets, growth register, birth and death register, sale register, auction sheets and other records maintained at the Swine farm of Livestock Production Management Section at Indian Veterinary Research Institute, Izatnagar, Uttar Pradesh. The pigs were housed under a loose housing system. They were grouped separately as per the respective age groups. Feeding and other management practices were kept constant. Data on a total of 215 Landly pigs was obtained for the years 2015-2018. These pigs were weighed at weekly intervals till 8th week. After 8 weeks of age, weighing was done at the interval of 4 weeks till 32 weeks of age. Data was categorized into male (69) and female pigs (146) and was fed to a program in the Statistical Analysis Software, MATLAB 2019 b.Analysis was conducted on the group of male pigs, group of female pigs as well as combined dataset using weight at 4 weeks, weaning weight and weight at 20 weeks of age to determine which can be best used for prediction. Gradient or difference in weight for 0-8 weeks viz. w1-w2, w2-w3, w3-w4, w4-w5, w5-w6, w6-w7, w7-w8, w8-w9 was calculated which was further used to calculate the average growth rate. The estimated weights were used to calculate the average error and standard error to analyze the reliability of the estimation. 
Estimation from week 4 was done using the formula as under:

Estimated value of weight at week $32=$ weight at week $4(\mathrm{y})+$ average gradient $* 28$ (where 28 is number of weeks from week 4 to week 32).

Estimation from week 8 was done using the formula as under:

Estimated value of weight at week $32=$ weight at week $8(y)+$ average gradient $* 24$ (where 24 is number of weeks from week 8 to week 32).

Estimation from week 20 was done using the formula as under:
Estimated value of weight at week $32=$ weight at week $20(y)+$ average gradient $* 12$ (Where 24 is the number of weeks from week 8 to week 32)

\section{Results and Discussion}

While estimating weight at week 32 using weight at week 4 (w4), average error and standard error were calculated which were 43.32 and 12.55 respectively for male pigs. Similarly, for female pigs value of Standard error and average error were -43.58 and 10.45 respectively. When combined data (male + female) was used values of standard error and average error were found to be -43.50 and 11.14 respectively.

Table.1 Average error and standard error for estimation of weight at week 32 from weight at week 4, 8 and 20

\begin{tabular}{|l|l|l|l|}
\hline Estimating weight at week 32 using & Group & $\begin{array}{l}\text { Average } \\
\text { error }\end{array}$ & $\begin{array}{l}\text { Standard } \\
\text { error }\end{array}$ \\
\hline \multirow{2}{*}{ 1. Weight at week 4(w4) } & Male & -43.32 & 12.55 \\
\hline \multirow{2}{*}{ 2. Weight at week 9(w9) } & female & -43.59 & 10.45 \\
\hline & Male + female & -43.50 & 11.14 \\
\hline \multirow{2}{*}{ 3. Weight at week 20(w20) } & Male & -43.12 & 12.90 \\
\hline & female & -43.55 & 10.81 \\
\hline & Male + female & -43.41 & 11.50 \\
\hline & Male & -23.64 & 10.34 \\
\hline & female & -24.49 & 8.18 \\
\hline & Male + female & -24.22 & 8.92 \\
\hline
\end{tabular}

Fig.1 Scatter plot of actual weight at week 32 vs estimated weight at week 32 using weight at week 20 in female pigs

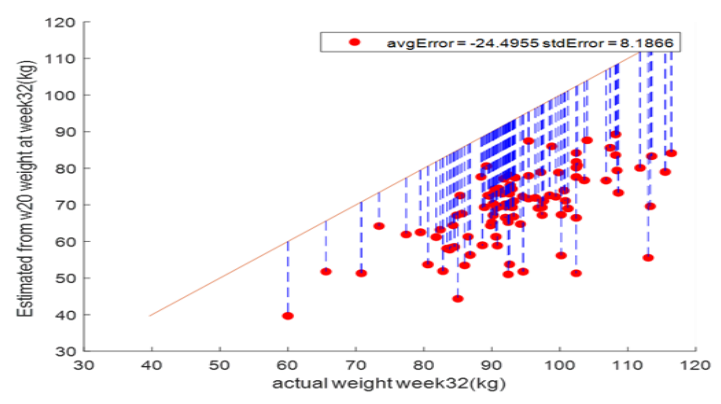


Fig.2 Scatter plot of actual weight at week 32 vs estimated weight at week 32 using weight at week 8 in female pigs

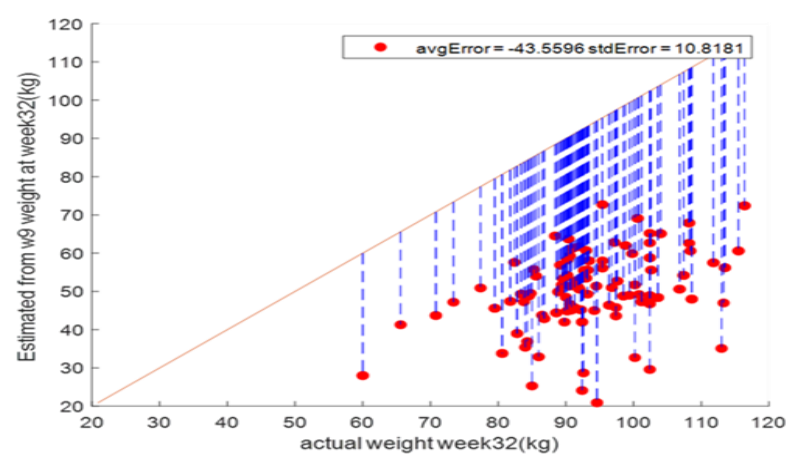

On similar lines estimation of weight at week 32 from weight at week 8 (w8) was done for which average error and standard error obtained were calculated which were -43.12 and 12.90 for male pigs respectively. Similarly, for female pigs values of Standard error and average error were -43.55 and 10.81 respectively (Fig. 2). When combined data (male + female) was used standard error and average error were found to be -43.41 and 11.50 respectively. While estimating weight at week 32 from weight at week 20(w20), average error and standard error calculated were -23.64 and 10.34 for male pigs, -24.49 and 8.18 for female pigs (Fig. 1) and -24.22 and 8.92 respectively when combined data (male + female) was used (Table 1).

Lowest standard error was obtained when prediction was done using weight at week 20 . This was followed by weight at week 4 which produced less standard error as compared to weight at week 9, for prediction. In all the groups female group had the least standard error and was followed by male group. The results indicate that the standard error is almost similar when weight at weeks 0,4 and 8 are used to predict the weight at week 32 . Weight at week 8 or weight at the time of weaning is no better than weight at week 20 or week 4 in predicting the final weight. Also, weight at week 20 has a lower standard error and is better than weight at week 9 for predicting the weight at week 32 but holds lesser significance as it is almost the marketing age for slaughter pigs.

From the above study it can be concluded that prediction of weight at week 32 from weight at week 20 produced the lowest standard error. Female pigs had the least standard error when estimation of weight at week 32 was done from weight at week 20. In all the age groups females have shown better predictive ability than males. Weight at week 20 can be used for prediction but it has lesser significance as the animals are already quite close to the marketable age at week 20 and prediction at this stage is more obvious. Results of estimation are similar both for pigs of week 4 age group and pigs of week 8 age group and contrary to the expectation that weaning weight can be a better predictor of adult weight.

\section{Acknowledgments}

The research was supported by the scholarship under CAAST-ACLH, NAHEP.

\section{Conflict of interest}

The authors declare that there is no conflict of interests regarding the publication of this paper. 


\section{References}

Brandl, N. and Jørgensen, E. 1996. Determination of live weight of pigs from dimensions measured using image analysis. Computers and Electronics in Agriculture. 15(1): 57-72.

Morris, J.E., Cronin, G.M., Bush, R.D., 2012. Improving sheep production and welfare in extensive systems through precision sheep management. Animal Production Science. 52, 665-670.

Schofield, C. P. 1990. Evaluation of image analysis as a means of estimating the weight of pigs. Journal of Agricultural Engineering Research. 47(4): 287-296. Schofield, C. P., Marchant, J. A., White, R. P., Brandl, N. and Wilson, M. 1999. Monitoring pig growth using a prototype imaging system. J. Agricultural Engineering Research. 72(3): 205-210.

Zaragoza, L.E.O. 2009. Evaluation of the accuracy of simple body measurements for live weight prediction in growingfinishing pigs [M.S. thesis], Graduate College of the University of Illinios Urbana Champaign.

\section{How to cite this article:}

Kumari, A., T. Dutt and Kumar, A. 2020. Estimation of Weight at 32 Weeks of Age using Weight at Week 4 (w4), Weaning Weight (w8) and Weight at 20 Weeks of Age (w20) in Crossbred (Landly) Pigs. Int.J.Curr.Microbiol.App.Sci. 9(12): 538-542. doi: https://doi.org/10.20546/ijcmas.2020.912.064 